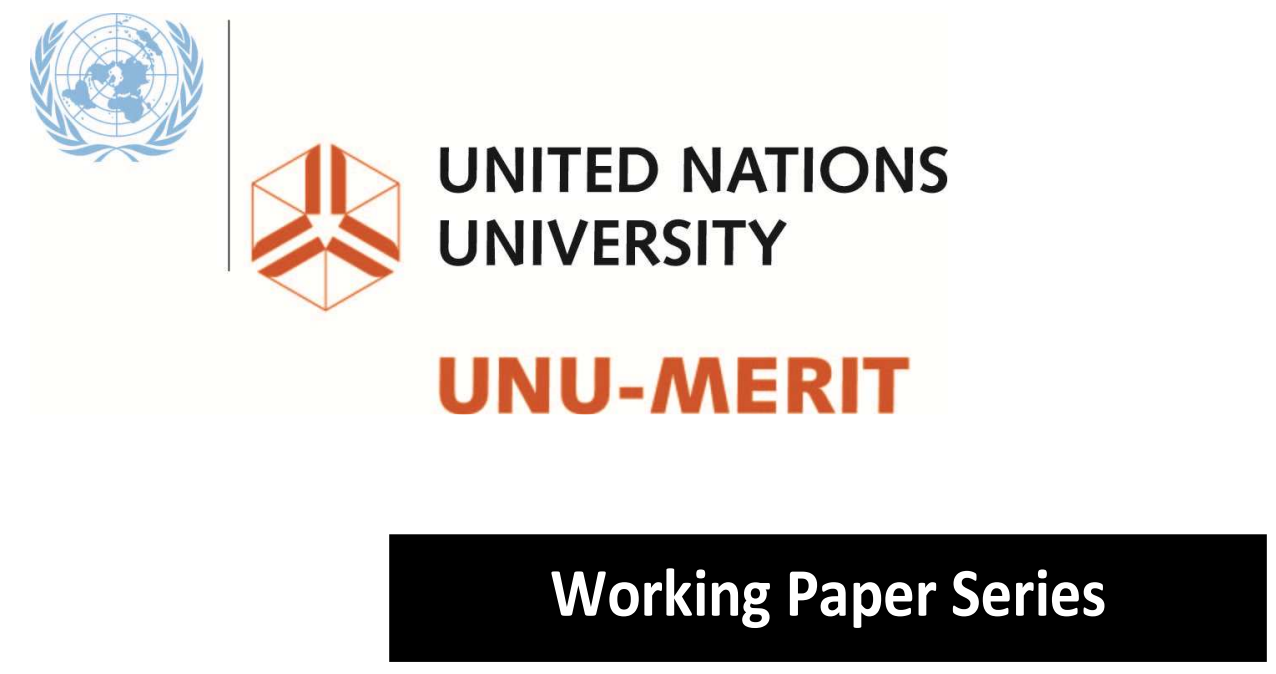

\#2012-044

Prescriptions for network strategy:

Does evidence of network effects in cross-section support them?

Joel A.C. Baum, Robin Cowan, and Nicolas Jonard

Maastricht Economic and social Research institute on Innovation and Technology (UNU-MERIT) email: info@merit.unu.edu | website: http://www.merit.unu.edu

Maastricht Graduate School of Governance (MGSoG)

email: info-governance@maastrichtuniversity.nl | website: http://mgsog.merit.unu.edu 
UNU-MERIT Working Papers

ISSN 1871-9872

Maastricht Economic and social Research Institute on Innovation and Technology, UNU-MERIT

Maastricht Graduate School of Governance MGSoG

UNU-MERIT Working Papers intend to disseminate preliminary results of research carried out at UNU-MERIT and MGSoG to stimulate discussion on the issues raised. 


\title{
Prescriptions for Network Strategy: Does evidence of network effects in cross-section support them?
}

\author{
Joel A.C. Baum*, Robin Cowan ${ }^{\dagger}$, and Nicolas Jonard ${ }^{\ddagger}$ \\ *University of Toronto \\ $\dagger$ University of Strasbourg and Maastricht University \\ $\ddagger$ University of Luxembourg
}

May 10, 2012

\begin{abstract}
Although intuitively appealing (and common), drawing network strategy implications from empirical evidence of network performance effects in pooled cross-section is not necessarily warranted. This is because network positions can influence both the mean and variance of firm performance. Strategic prescriptions are warranted if empirically observed network effects reflect increases in mean firm performance. If network effects reflect increases in firm performance variance, however, such prescriptions are warranted only if the increase in the odds of achieving high performance is sufficient to compensate for the concomitant increase in the odds of realizing poor performance. Our simulation study, designed to examine network performance effects in both pooled cross-section and within-firm over time across a wide range of conditions, counsels caution in drawing implications for network strategies. We discuss the implications of our findings for research on network effects, and more broadly for drawing strategic inferences from studies of firm performance in pooled cross-section.
\end{abstract}

\section{Introduction}

At the intersection of network and strategy literatures, researchers are concerned with how patterns of strategic alliances create network-based advantages for well-connected firms. Researchers have examined whether firms should occupy densely interconnected "closed" net- 
work positions, which afford coordination and integration benefits by facilitating the ease of exchange and commonness of information among firms (Coleman, 1988, 1990), or in sparsely interconnected "open" network positions, which confer information access and control benefits through conveyance of diverse information and resources and brokerage opportunities (Burt, 1992, 2000; Granovetter, 1973).

Despite empirical evidence remaining somewhat equivocal, the idea of "network effects" on firm performance is by now uncontroversial, and attention focused increasingly on the identification of conditions under which open or closed network positions are more or less advantageous (e.g., Ahuja, 2000; Baum et al., 2010; Burt 1998, 2000; Rowley et al., 2000). What remains uncertain, however, is whether the evidence of "network effects" supports commonly inferred prescriptions for "network strategy," where the former is typically based on empirical estimates from panel or pooled time-series-and-cross-section data showing that firms occupying a particular type of network position at time $t$ outperform firms that do not at time $t+1$, and the latter is based on the inference that firms sustaining the type of network position shown to be beneficial in pooled cross-section, will outperform those that do not over the longer term.

Although such an inference is intuitively appealing, the implications of network effects in cross-section do not translate straightforwardly into implications for sustained network strategy. This is because network positions can affect both the mean and variance of firm performance outcomes, which play distinct roles in competition for high performance (March, 1991). If a network position increases both the mean and variance of performance, the firm gains a performance advantage over its rivals. A network position advantage may also be gained if the increase in performance variance is sufficient to compensate for a decrease in mean performance, and vice versa. When competition is for primacy at a given point in time, increasing the variance, rather than the mean, of performance contributes increasingly to competitive advantage as the number of competitors increases (March, 1991).

But increased performance variance also exposes firms to a greater risk of very poor performance, and, as a result, the benefit of increasing firm performance variance depends importantly on the distribution of possible performance outcomes. The likelihood of achieving high performance, in particular, depends on the right-hand tail of the performance distribution; the left-hand tail is critical to experiencing poor performance. If the distribution is right skewed, with only a small number of high-performance outcomes available relative to poor 
ones, increasing performance variance improves a firm's chances of achieving one of the high outcomes, but the increased odds may be to too small to compensate for the reduction in the mean that results from the concomitantly higher odds of obtaining poor outcomes.

The implication of these observations is consequential: if empirical evidence of network effects in pooled cross-section reflects the influence of firms' network positions at time $t$ on the variance, rather than the mean, of their performance at time $t+1$, whether network positions associated with high performance in cross-section may also prove beneficial if sustained over time depends on whether the increased odds of achieving high performance are nullified by a concomitant rise in the risk of experiencing poor outcomes.

Three factors suggest both that empirical findings for network effects plausibly reflect performance variance (rather than mean) effects and that such nullification is therefore likely. One is that empirical studies of network effects model the role of network position in achieving high performance in pooled cross-section, which is governed by performance variance, rather than avoiding low performance, which is governed by mean performance (March, 1991). A second is the commonly observed right-skewness of firm performance distributions (e.g., Adriani and McKelvey, 2009; Powell, 2003), which suggest that increased performance variance may often raise firms' risk of low performance more than their chances of achieving high performance, and thus reduce their mean performance. The third is that analyses of performance in pooled cross-section are informed by performance variation across rather than within firms, and thus indifferent to which particular firm performs well in each cross section. As a result, while firms occupying a particular type of network position may tend to achieve high performance in any given cross section, it may be different firms achieving the high performance in each instance.

In this paper, we assess the extent to which network strategies can be inferred from network effects empirically observed in pooled cross-section. We focus on firm performance effects of open and closed network positions, both because they are the main focus of influential contemporary empirical work on network effects, and because of their distinct performance implications. In particular, recent empirical research (e.g., Ahuja, 2000; Rothaermel and Deeds, 2004; Rowley et al., 2000) suggests that open network positions facilitate exploratory (non-local) search, which increases firms' performance variance, while closed network positions facilitate exploitive (local) search, which lowers firms' performance variance (Holland, 1975; March, 1991). 
Our approach is simulation based. This approach allows us to examine performance in both pooled cross-section and within-firm over time across a wide range of skewness of possible performance outcomes. Our simulation model is designed to characterize innovation networks and outcomes, for which the role of strategic alliances in the acquisition of external knowledge is well established (Powell et al., 1996; Rosenkopf and Almeida, 2003; Rosenkopf and Nerkar, 2001), exploitation and exploration activities are highly germane (Gilsing et al., 2008; Lavie and Rosenkopf, 2006; Rothaermel and Deeds, 2004; Rowley et al., 2000), network effects have been an important focus of research (e.g., Ahuja, 2000; Powell et al., 2005; Rowley et al., 2000), and distributions of possible performance outcome are known to be variously skewed (Abernathy and Utterback, 1978; Tushman and Anderson, 1986).

After developing our theoretical predictions regarding firms' network positions and performance variation more fully, we describe and validate our simulation model, demonstrating that, across a wide range of distributions of possible firm performance, the model replicates both the properties of "real world" networks, as well as network effects on performance in pooled cross-section that mirror those obtained in empirical network studies. Subsequently, we turn our attention to network strategies, and specifically, to the questions of 1) whether network positions associated with high performance in pooled cross-section are also beneficial when sustained in the long run, and 2) how the skewness of distributions of possible firm performance impacts the veracity of conclusions for network strategy drawn from network effects observed in pooled cross-section.

\section{Network position and performance}

Although network theorists agree that "better-connected" firms gain a competitive advantage, there is disagreement regarding what "better-connected" actually means. Coleman's (1988) closure argument implies that firms are better off occupying densely interconnected, closed network positions in which their partners are also partners. Burt's (1992) structural hole argument, in contrast, prescribes that firms embed themselves in sparsely connected, open network positions comprised of disconnected partners. Rather than arguing the superiority of one network position over the other, Burt (1998, p. 45) suggests a contingency approach to reconcile this disagreement: "Closure and hole arguments are not as contradictory as they might seem... The ambiguity stems in large part from the different roles that 
social capital plays in the study populations with which each is justified." Open and closed network positions afford distinct benefits that are useful for different purposes, and understanding their effects requires consideration of the conditions under which firms benefit from possessing the distinct benefits they afford.

Consistent with Burt's (1998) view, recent studies have pursued contingency approaches in which the benefits of open and closed network positions depend on environmental conditions and task purposes (Ahuja, 2000; Rothaermel and Deeds, 2004; Rowley et al., 2000). These approaches conceive the appropriate type of network position to depend on their differential value for exploitive and exploratory learning modes. That is, the degree to which firms are focused on exploiting existing technologies, skills, and information, or exploring the environment for emerging innovations and other significant changes.

Exploitation involves using existing knowledge to improve organizational functioning by reducing variability in the quality or efficiency of current strategies, competencies, technologies and procedures. In exploitation, the emphasis is on refining existing knowledge by gathering specific information that will provide deeper understanding in a particular area. The solution space is thus well defined, and search is local and highly specific. The classic exemplar is the well-known "experience curve" phenomenon in which firms reduce production cost and/or time by eliminating redundancies and inefficiencies through continuous tuning of internal practices and processes (Yelle, 1979; Argote, 1993). Exploration, in contrast, entails processes of concerted variation and experimentation to identify new ways of doing things and new things to do. Because the focus is on gathering information and identifying emerging innovations and alternative future options, in exploration, the solution space is ill-defined, search is wide, and a premium is placed on newer, more diverse information.

March (1991) views both processes as essential, but observes that firms face a trade-off between how much to invest in refining existing technologies to stay competitive in their current markets in the short term, compared to developing new knowledge about novel technologies with which to compete over the long term as environmental demands change. The balance of resources firms allocate to exploitation and exploration thus tends to depend on environmental conditions (Lant et al., 1992; Rowley et al., 2000). Environmental uncertainty, in particular, by affecting the predictability and frequency of change (Dess and Beard, 1984), influences the degree to which firms must emphasize refinement of existing knowledge and/or seek out new opportunities. In uncertain environments firms must allocate more resources 
to exploration than in stabler environments in which there is greater clarity about future directions and fewer environmental disturbances.

The distinct information requirements of exploitation and exploration suggest different prescriptions regarding appropriate network position (Gilsing et al., 2008; Rowley et al., 2000). Open network positions, comprised of disconnected, non-redundant partners, are ideal for gaining access to diverse sources of information and knowledge, to facilitate identification of emerging opportunities and threats, and location of complementary knowledge (Powell et al., 1996; Mitsuhashi, 2003). Open network positions thus afford a firm unique information and perspectives from each of its partners that facilitates broad search for emerging innovations and alternative future options. In uncertain environments requiring large investments in exploration, sparsely connected, open network positions are therefore expected to be advantageous. Closed network positions, by contrast, inhibit firms' access to broader, divergent, distant, and less familiar approaches critical to exploration (Uzzi, 1996, 1997). Although this limits their usefulness in meeting the demands of uncertain environments, the access to redundant and validating information they afford is essential to meeting the information requirements of exploitation (Dyer and Singh, 1998; Van de Ven, 1976; Walker et al., 1997). The ability to triangulate across multiple, redundant sources enhances evaluation of acquired information obtained from each source, aiding in refinement of existing knowledge. In stable, certain environments requiring large investments in exploitation, closed network positions are thus expected to be advantageous.

Combined, the previous arguments offer clear predictions regarding the value of open and closed network positions: Firms operating in a rapidly changing environment are expected to benefit from open network positions facilitating exploration, while firms in a stable environment are expected to benefit from closed network positions facilitating exploitation.

To this point, we have grounded our discussion in social networks literature. Similar predictions follow, however, from March's (1991) reasoning on firm strategies that change the mean and/or variance of their performance distributions. The starting point for March's argument is a very general one: when observing a population of firms at any point in time, the highest performing firms will tend to be those having the highest variance performance distribution. Thus in cross-section, the correlation between firm performance and varianceincreasing strategies will tend to be positive. Moreover, as the aggregate, population-level performance distribution becomes more right-skewed, this correlation should tend to increase. 
To see this, consider Figure 1. As the figure shows, holding mean performance in the population constant, increasing the right skew of the population-level performance distribution raises both the density of the right tail and the mass near zero. As a result, increasing the skew of possible population-level performance outcomes also increases the odds that high performance variance firms are the best performers in the population.

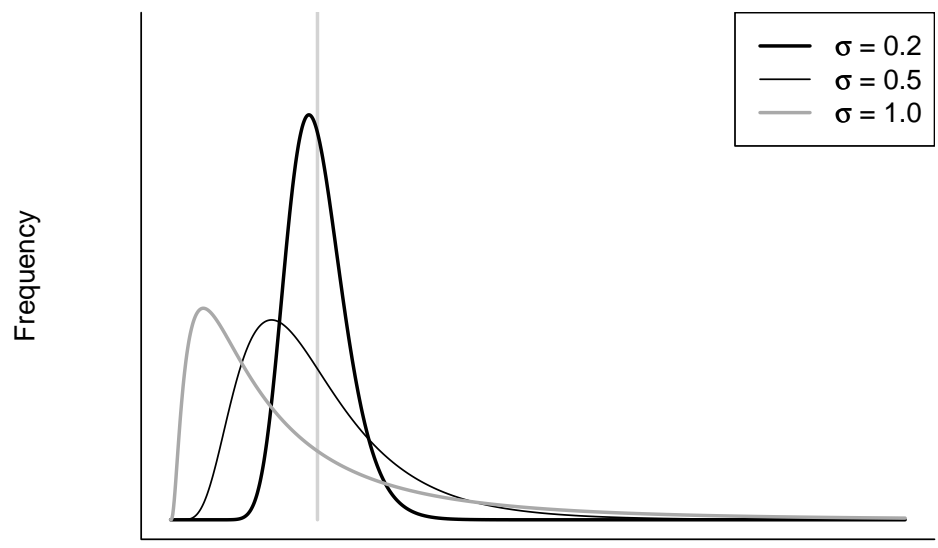

Performance

Figure 1: Showing the effects of increasing skewness of population-level performance distributions. Log-normal distributions with constant mean (of 1 , shown by the vertical line) and increasing both variance and skewness moving from thick black to thin black to grey.

In a network context, open positions represent variance-increasing strategies (Burt, 1992). Consequently, as the probability of occasional, very large, disruptive innovations (and thus the right-skewness of the population-level performance distribution) increases, the performance of firms occupying open network positions should increase in pooled cross-section. By the same logic, as the probability of such large, disruptive innovations falls, and innovation in the population becomes largely incremental, the performance of firms occupying variancereducing closed network positions should increase in cross-section. These predictions match both theoretical arguments and empirical findings in pooled cross-section studies of network effects (e.g., Ahuja, 2000; Gilsing et al., 2008; Rothaermel and Deeds, 2004; Rowley et al., 2000). 
Now, rather than in cross-section, consider the longer-term implications of firms attempting to strategically manipulate the moments of their performance distributions over time via their network positions. Variance-increasing open network positions raise both the value of the firm's high performance outcomes and lower the value of its poor performance outcomes. The implications of these two effects for a firm's long-run performance depend on the skewness of the aggregate, population-level performance distribution. As illustrated above in Figure 1, holding mean performance constant, increasing skewness raises both the right tail density and the mass of very poor outcomes. As a result, when the skew of the population-level performance distribution is low, high firm-level performance variance improves a firm's odds of very good outcomes, but not of very poor outcomes given their relatively small frequency. As the skew of the aggregate performance distribution increases, however, a high variance firm strategy raises not only the odds of very good outcomes, but also, increasingly, of very poor outcomes. In contrast, while a low variance firm strategy does not increase the odds of very good outcomes, it does afford protection against very poor outcomes. The long-term effect of sustaining open and closed network positions on firm performance should thus depend on the skewness of the population-level performance distribution. Specifically, the long-term performance of firms sustaining open network positions should decline with the right-skewness of the population-level performance distribution, while, oppositely, the long-term performance of firms sustaining closed network positions should increase with the right-skewness of the population-level performance distribution. Table 1 summarizes our theoretical predictions. Note that the predictions are opposite not only between open and closed network positions, but also for performance in cross-section and over time within each network position, complicating inferences for firm strategy from evidence in pooled crosssection.

\begin{tabular}{|c|c|c|c|}
\hline $\begin{array}{l}\text { Network } \\
\text { position }\end{array}$ & $\begin{array}{l}\text { Effect on } \\
\text { firm perf. }\end{array}$ & $\begin{array}{l}\text { Performance in } \\
\text { cross-section }\end{array}$ & $\begin{array}{l}\text { Performance } \\
\text { over time }\end{array}$ \\
\hline 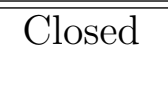 & $\begin{array}{c}\text { Variance } \\
\text { decreasing }\end{array}$ & $\begin{array}{c}\text { Decreases with skewness of } \\
\text { population-level perf. distribution }\end{array}$ & $\begin{array}{c}\text { Increases with skewness of } \\
\text { population-level perf. distribution }\end{array}$ \\
\hline Open & $\begin{array}{l}\text { Variance } \\
\text { increasing }\end{array}$ & $\begin{array}{l}\text { Increases with skewness of } \\
\text { population-level perf. distribution }\end{array}$ & $\begin{array}{c}\text { Decreases with skewness of } \\
\text { population-level perf. distribution }\end{array}$ \\
\hline
\end{tabular}

Table 1: Predictions of firm performance effects of open and closed network positions in different environments. 


\section{Model}

In this section we develop a model aimed at elaborating the arguments presented above. Although many strategies likely affect the variance of firm performance, here we focus on network strategies, drawing inspiration from the extensive literature on the sources of value of open and closed network positions. We also follow this literature in framing our model in the context of firms allying in order to innovate, and formalize the exploration-exploitation spectrum by focusing on the properties of innovations that take place. Specifically, we assume that an exploitation environment, innovations tend to be of similar importance, and thus we can see innovation "size" as being drawn from a distribution with relatively low skewness. However, in an exploration environment, there can be wide differences in the effects of innovations; most are small, and have little impact, but when a large innovation does arrive, it can be highly disruptive. With this formalism we capture very simply the effects of the population-level technological environment as it favors exploration or exploitation as means of successful innovation.

\subsection{Sketch of the model}

We first describe the model verbally, and then specify the formalization we use in implementation.

Firms ally for the purpose of innovating and in so doing they create an industry network. Three forces shape the evolution of that network.

The first is the process of alliance formation. Firms form alliances with the goal of creating innovations, and for any firm, each alliance represents one R\&D project. ${ }^{1}$ An alliance is in essence an institution for knowledge sharing, so a firm forms an alliance with another firm in order to access the knowledge it needs to (potentially) make that project successful. The need to have complementary knowledge for successful innovation implies that partners will be neither too close together nor too far apart in knowledge space, and the probability that a firm succeeds through a particular alliance is a positive, single-peaked function of the distance in knowledge space from the firm to its partner in that alliance. Because the knowledge space is a metric space, this need for proximity will induce some amount of local correlation in the decisions to ally, yielding both repetition and cliquish-ness in firms' partnering decisions

\footnotetext{
${ }^{1}$ For simplicity, we assume that firms undertake no R\&D outside alliances.
} 
(Baum et al., 2010).

The second force shaping the alliance network is learning. When two firms ally, they learn from each other, and so move closer together in knowledge space. This can affect their suitability as partners in subsequent periods.

The third, and most important, driving force in the model is innovation. When a firm produces an innovation, it disrupts the activities of all other (non-innovating) firms. In response, firms rearrange their activities by deploying different knowledge than they did before the innovation. An innovation thus changes the value of the knowledge stocks of other firms; and it changes the value of partnerships between firms (represented by their specific knowledge endowments). We compress this into a single action, in which non-innovating firms are relocated in knowledge space, thereby changing the value of their (potential) partnerships, and the innovating firm (if any) receives a value equal to the total displacement of other firms in knowledge space. As a consequence, firms can calculate the expected benefit of any possible alliance as the product of its success probability and the total dislocation the firm can expect to impose on other firms in the industry, minus alliance cost. Alliances form when expected profits are positive for both partners.

In each period all actual and potential alliances are (re)evaluated. If a potential alliance shows positive expected profits it forms, or is maintained. If an existing alliance shows negative expected profits it is terminated. Combined, the decisions of firms to ally with profitable partners, their learning from one another, and their dislocation in knowledge space in response to innovations produce networks that exhibit features common to "real world" networks. In the following sections we operationalize these assumptions, taking each element of the process individually.

\subsection{Firms and the arrival of innovations}

A fixed, finite population of $N$ firms is located in a 2-dimensional metric knowledge space, which we take to be unit square $[0,1]^{2}$, with periodic structure (i.e. a torus). Each firm is characterized by a knowledge endowment, $v_{i}=\left(v_{i, 1}, v_{i, 2}\right)$, fori $=1, \ldots, N$, which defines its location in knowledge space.

We treat innovations as stochastic, and independent across firms. Each firm engages in knowledge sharing with each of its alliance partners, and each alliance formed by the focal firm contributes additively to the probability that this firm succeeds in this period. The 
marginal contribution of a particular alliance to the firm's project portfolio is its success rate, which in turns depends on the characteristics of the alliance.

Specifically, the success rate for any alliance depends of the "goodness of fit" of the alliance, which is assumed to be a single-peaked function of the Euclidean distance (with a maximum at finite distance $d^{*}$ ) between the alliance partners in knowledge space. ${ }^{2}$ Formally, we employ a bell-shaped (Gaussian) function to map knowledge-distance to one-period success rates, according to

$$
\lambda_{i j} \equiv f\left(d_{i j}\right)=\bar{\lambda} e^{-\left[\left(d_{i j}-d^{*}\right) / \sigma\right]^{2}},
$$

where $d_{i j}$ is the distance in knowledge space between $i$ and $j$,

$$
d_{i j}=\left[\sum_{\ell=1,2}\left(1 / 2-|1 / 2-| v_{i, \ell}-v_{j, \ell}||\right)^{2}\right]^{1 / 2}
$$

and $\bar{\lambda} \ll 1$ is a scaling parameter which we use to control the maximum success probability. Firm $i$ 's overall success rate is $\lambda_{i}=\sum_{i j \in g} \lambda_{i j}$, where $g$ is the network of existing alliances during the period we consider. The population-level arrival rate of innovations is $\lambda=\sum_{i=1}^{N} \lambda_{i}$. Provided success rates are small enough $\left(\lambda_{i j} \leq \bar{\lambda} \ll 1\right)$, any firm's overall success rate $\lambda_{i}$ is also small, and thus the population-wide arrival rate of innovations $\lambda$ is less than one, in which case at most one firm succeeds in any period. We impose parameter values such that this constraint is satisfied.

\subsection{Dislocation following an innovation}

Following an innovation, the knowledge landscape changes, altering the value of different types of knowledge and different knowledge combinations. We assume that an innovation by firm $i$ disrupts the status quo for all other firms. Firms respond by deploying new knowledge in their activities, and so an innovation changes both where firms are located in space and which combinations of knowledge are valuable. The extent to which a non-innovating firm is

\footnotetext{
${ }^{2}$ Empirical studies have shown, in a variety of contexts, that alliance and merger success is driven by partners' relative knowledge endowments. This is commonly formalized using "distance in knowledge space", which is measured in a variety of ways. Additionally, recent work has shown that the probability that a pair of firms forms an alliance is concave in their distance in knowledge space (e.g., Ahuja and Katila, 2001; Mowery et al., 1996, 1998; Mueller et al., 2009; Rothaermel and Boeker, 2008; Schoenmakers and Duysters, 2006; Stuart, 1998).
} 
affected by an innovation is determined both by its proximity to the innovating firm, and by the size of the innovation. We operationalize this by assuming that following an innovation, firms are dislocated in the knowledge space. More precisely, following an innovation by firm $i$, firm $i$ itself is not moved but all other firms are dislocated as a function of their distance to $i$ in knowledge space.

Any firm $j$ is relocated, uniformly at random within a disk centered on $j$ 's pre-innovation location. The disk has radius

$$
r_{j}=\theta \cdot r_{\max }\left(1-\sqrt{2} d_{i j}\right)
$$

where $r_{\max }$ is the maximum possible dislocation, $\sqrt{2} / 2$ is the maximum possible distance between firms and $\theta$ measures the size of the innovation. Firms are affected by an innovation as a linear function of their distances to the innovating firm. The magnitude of this distance effect, however, depends on the size of the innovation, $\theta$. Innovation size is treated as a positive, multiplicative shock, drawn from a binary random variable with expectation equal to 1 and variance and skewness which we control with the parameter $s$. By changing the skew of the innovation size distribution, we control the nature of the technological regime in which firms operate, and thus the skew of the population-level performance distribution.

Define realized dislocation of firm $j$ as $\delta_{j} .{ }^{3}$ Total dislocation from an innovation is thus given by

$$
V_{i}=\sum_{j \neq i} \delta_{j}
$$

The expected magnitude of the dislocation of firm $j$ being $r_{j} / 2$, total expected dislocation, used by firms to calculate expected values of an alliance, is

$$
\mathbf{E}\left[V_{i}\right]=\sum_{j \neq i} E\left[r_{j}\right]=E[\theta] \cdot \sum_{j \neq i} r_{j} / 2=\sum_{j \neq i} r_{j} / 2 .
$$

\subsection{Strategic alliance formation}

The value to firm $i$ of a particular alliance $i j$ is the marginal contribution of that particular alliance to the firm's expected profit, net of alliance cost $c$. The marginal contribution of

\footnotetext{
${ }^{3}$ In terms of implementation, the direction of motion of firm $j$ is an angle drawn uniformly at random in $[0,2 \pi)$; distance of dislocation of $j, \delta_{j}$, is drawn from a uniform distribution $U\left[0, r_{j}\right]$.
} 
alliance $i j$ to the success rate of firm $i$ is $\lambda_{i j} .{ }^{4}$ If $i$ innovates, the value of that innovation is the sum of the dislocations it imposes on all other firms, as in Equation 4. We can thus write the expected value of alliance $i j$ to firm $i$ as

$$
\pi_{i}^{i j}=\lambda_{i j} \cdot E\left[V_{i}\right]-c
$$

the product of $\lambda_{i j}$, the marginal contribution of alliance $i j$ to the success rate of firm $i$, and the dislocation $i$ expects to impose on other firms, net of alliance cost $c$.

An alliance will form if expected profits are positive to both partnering firms. Rewriting, the alliance (formation or continuation) condition is thus

$$
\lambda_{i j} \cdot E\left[V_{i}\right] \geq c \text { and } \lambda_{i j} \cdot E\left[V_{j}\right] \geq c .
$$

\subsection{Learning}

If firms $i$ and $j$ ally, they learn from each other, and so move closer together in knowledge space. ${ }^{5}$ We model this as a linear partial adjustment process

$$
v_{i, 1}^{t+1}=\alpha v_{j, 1}^{t}+(1-\alpha) v_{i, 1}^{t} \text { and } v_{i, 2}^{t+1}=\alpha v_{j, 2}^{t}+(1-\alpha) v_{i, 2}^{t},
$$

where parameter $\alpha \in(0,1 / 2)$ measures absorptive capacity in the industry.

In each period the industry network thus consists of the alliances formed by all firm pairs satisfying the condition in Equation 7. However, in a dynamic industry, we observe that knowledge portfolios, alliances and the industry network all change over time. At the population level, the industry network structure is determined by (current) knowledge stocks of the firms in it. But the network structure is instrumental in the innovation within the industry. Innovations force firms to respond, and to redeploy their knowledge, possibly using different knowledge in reaction to the new market conditions created by the innovation. Thus innovations change firms' position in the knowledge space, by forcing them to use different knowledge than they had done previously. So at the population-level, network structure and industry knowledge profile co-evolve. In the sections that follow, we explore this co-evolution

\footnotetext{
${ }^{4}$ We assume that innovations do not compete in any after-market, so firms can treat each alliance decision independently from all others, both their own and other firms'.

${ }^{5}$ This feature of alliances has been documented by Mowery et al., 1998; Uzzi, 1997.
} 
through numerical simulation of the model.

\section{Numerical implementation of the model}

The single period outcome of the model is easily characterized. There is a unique (pairwise stable) equilibrium in which all pairs of firms $i j$ and only those pairs such that the condition in Equation 7 holds form (or continue) an alliance. Over time however, the model being one of of complex co-evolution, its behavior does not lend itself to analytical solution. We resort to numerical simulation, with the following settings.

We consider a population of $N=100$ firms, and use as the knowledge space the unit torus. Thus each firm's knowledge endowment is a pair of positive real numbers, $0 \leq v_{i, 1}, v_{i, 2} \leq 1$, for all $i=1, \ldots, 100$. At the outset, all firms hold knowledge endowments distributed uniformly over the unit torus. We set the optimal distance to $d^{*}=0.025 .{ }^{6}$ We set $\sigma$, the parameter that governs how fast success probabilities fall as firm-pairs deviate from the optimal distance, at 0.025. This implies we are quite demanding in terms of being close to the optimal distance: two firms located on top of each other would only have a success rate of roughly one third of the maximum success rate $\bar{\lambda}$. The upper bound to the success rate of an alliance (which is achieved when participants are at the optimal distance) is $\bar{\lambda}=0.004$, as visible in Equation 1. The maximum possible dislocation following an innovation is 0.05. Absorptive capacity, $\alpha=0.01$. The cost of forming and maintaining an alliance is set to $c=0.000001$.

These parameters produce a reasonably dense network of average degree near five (i.e., a density of roughly $5 \%$ ), and an industry-wide arrival rate of innovations of about 0.3 (i.e., on average one innovation every third period). The network is sparse enough for network-effects to materialize, and the arrival rate of innovation is low enough to keep inertia in the network. Numerous explorations around the values we use here have no produced significant variation in the nature of the results.

Finally, we control the nature of the innovation regime using the log-normal distribution from which the innovation size is drawn (Section 3.2). For each innovation, size $(\theta)$ is drawn independently from a binary random variable taking the value $s$ with probability $1 /(s+1)$ and the value $1 / s$ with probability $s /(s+1)$, with $s \geq 1$. Then we get $E[\theta]=1$ and

\footnotetext{
${ }^{6}$ We set $d^{*}$ to a small value because we have in mind a very broadly defined industry such that of absorptive capacity and the need for novelty, the two forces generally taken to combine to produce the inverted-U relationship, absorptive capacity dominates.
} 
$V[\theta]=(s-1)^{2} / s$, which is a mean-preserving multiplicative random shock that we use to control the variance, skewness and higher moments of the innovation size, and thus, population-level performance distribution. We generate 500 random values of $s \in[1,30]$, each with equal mean innovation size/firm performance.

The experiment is run by initializing the firms' knowledge endowments uniformly at random over the unit torus. Alliances form each period according to the condition in equation 7 . Innovations arrive randomly, determined by the independent Poisson processes of the set of alliances as described in Subsection 3.2. We discard the initial 500 periods, to avoid any possible spurious effects arising from the initialization, and run the alliance formation/innovation process for 10,000 periods. We repeat this for 500 different values of $s \in[1,30]$.

\section{Results}

We examine some aggregate properties of the alliance network, before turning to a more detailed analysis of the relationship between position and performance.

\subsection{The network: snapshots and dynamics}

As a first step in the analysis, we display in Figure 2 two representative networks captured in period $t=1000$ in two runs of the model, one having a low skewness of the innovation size distribution (left panel, $s=2$ ), the other having high skewness (right panel, $s=30$ ). Standard network descriptive statistics are given.

Here we obtain a first intuition about the effect that the skewness in the innovation size distribution has on network structure. This effect is dynamic rather than static. Indeed, at any point in time, firms make alliance decisions based on expected profits, disregarding higher moments of the innovation size distribution. So for given firm locations, the alliance formation decisions are independent from $\theta$ (recall that mean innovation size remain constant across values of $s$ ). However, innovation interacts with learning. Over time, the effect of the latter is to bring firms closer in knowledge space. The low-skew innovation regime $(s=2)$ has frequent innovation of roughly constant magnitude $(\theta)$, counter-balancing the effect of learning in terms of increasing the clustering of firms in knowledge space. The high-skew regime $(s=30)$, in contrast, has many very small innovations whose effect is nullified by learning, and only rarely large ones. So most often in time, firms will be closer in knowledge 

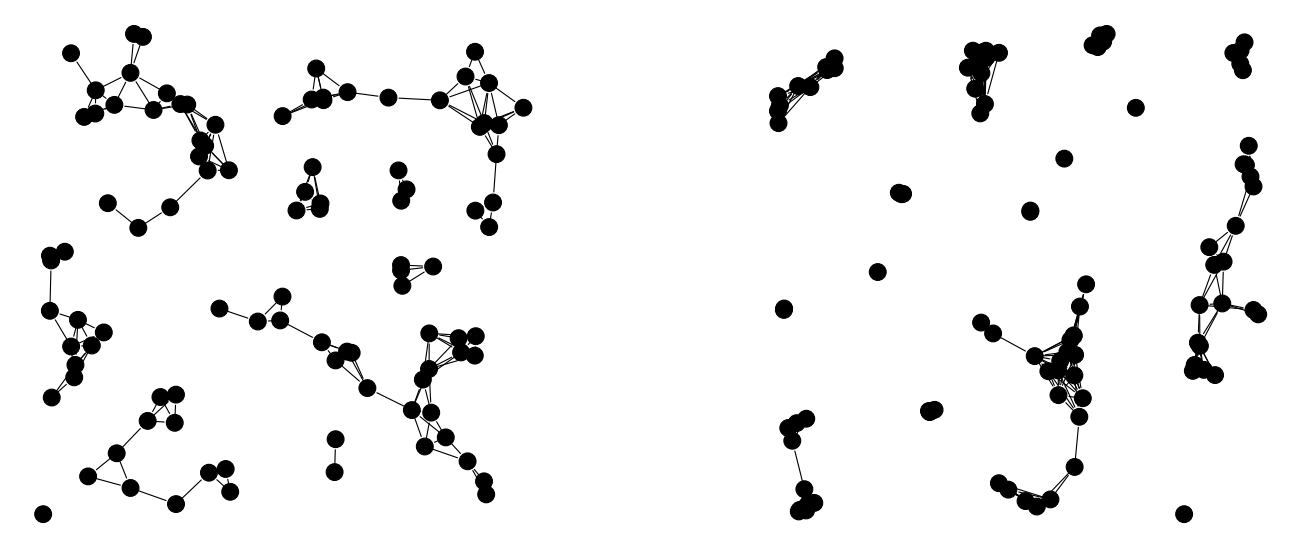

Figure 2: Two representative networks for low-skew (left panel, $s=2$ ) and high-skew (right panel, $s=30$ ) innovation distributions at period $t=1000$. The network on the left panel (right panel) is characterized by: average degree: 3.78 (5.84); average clustering: 0.73 (0.87); average betweenness: 17.16 (8.3); average constraint: 0.65 (0.54); average distance among reachable pairs: 3.25 (2.30); number of connected components: 10 (15).

space in a highly skewed regime, with higher average degree and clustering, and consequently more connected components and shorter distance among reachable pairs (within the smaller, denser components).

These intuitions are confirmed by Figure 3, which displays average degree and average clustering for the final 500 periods of two representative histories of the network, one for lowskew (left panel, $s=2$ ) and the other for a high-skew (right panel, $s=30$ ) innovation regimes. As firms ally, learn, innovate and are dislocated by others' innovations, the distribution of firms over the knowledge space changes, and so the alliances formed change. This implies a co-evolution between knowledge endowments and network behavior.

In both cases we observe that network activity (degree and clustering) rises and falls over time, however, the patterns are differ markedly for low and high-skew innovation regimes. In the low-skew regime, fluctuations are homogeneous over time. In the high-skewed regime, there is in general very little movement from one period to the next, and the effect of learning dominates. Firms in a given connected component get closer in knowledge space, forming more alliances (also among partners of a given firm) as global convergence takes place toward 

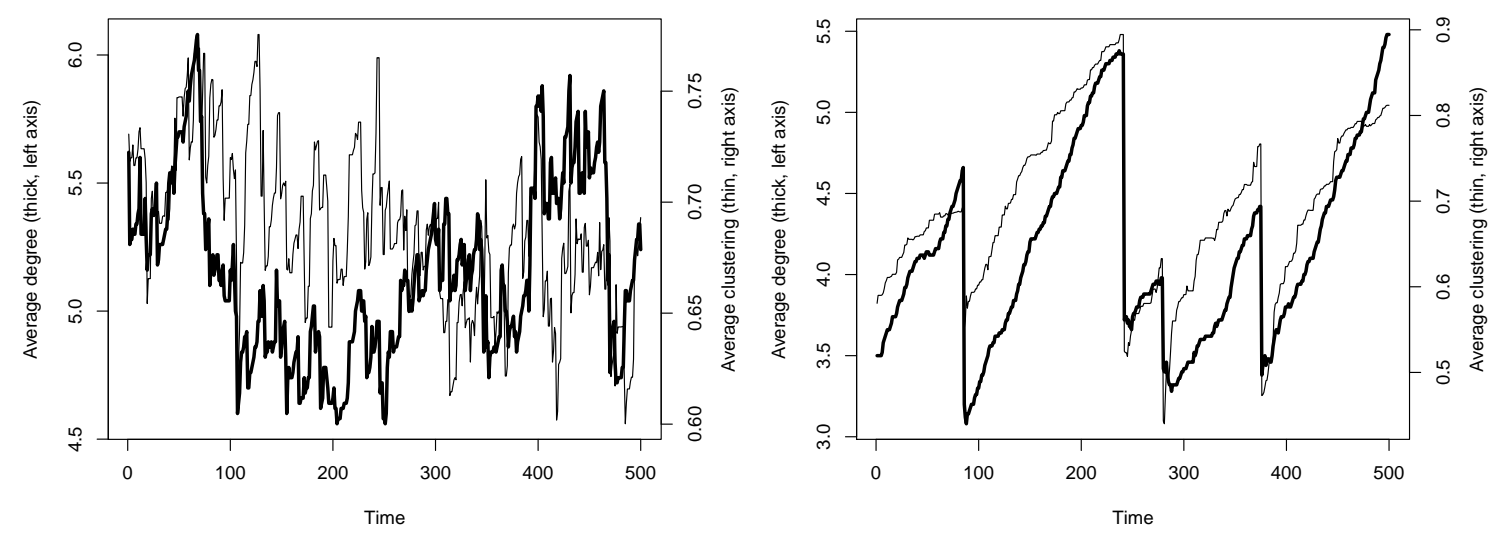

Figure 3: Time series of average degree and average clustering for low-skew $(s=2$, left panel) and high-skew ( $s=30$, right panel) innovation distributions.

the center of gravity of the set of connected firms. Innovation size $(\theta)$, is typically so small that their effect is overwhelmed by the learning process. But, infrequently, a very large, disruptive innovation occurs, and dislocates many firms. Degree and clustering then fall significantly, before routinized learning again takes command.

We can use this observation to address the interpretation of the parameter $\theta$ given above. We would expect in an era or industry where exploitation dominates that each period there is some small innovation. Most innovation attempts are successful and of comparable importance. In a period of exploration, however, we would expect that most innovation attempts are relatively unsuccessful. Every now and then, however, there will be a success, and it can be big enough to cause major disruptions in the industry.

\subsection{Network position and performance}

Our overarching concern is whether prescriptions for firm strategy can be derived straightforwardly from empirical findings in pooled cross-section. In the context of interfirm alliance networks, this is framed in terms of open versus closed network positions. In this section we tackle this issue directly. There are two ways to think about the relationship between firms' network positions and their performance. In the first, the locus is the innovation: what determines the size of an innovation? This is the pooled cross-section approach. In the second, 
the locus is the firm: what determines the size of a firm's innovative performance? This is the within-firm, over time approach, which is relevant for strategic prescriptions. We ask both questions and examine whether the answers are consistent with or, as we predict, opposite to, each other, and thus whether or not evidence of network effects in pooled cross-section data supports prescriptions for network strategy over time.

For comprehensiveness, we do this with two alternative measures. Node betweenness is a direct measure of the openness of a network position. ${ }^{7}$ Betweenness is large when a firm connects two otherwise disconnected (or very distant) parts of a network. Such a firm occupies a fairly unique, open position in terms of accessing and controlling access to a broad set of diverse resources. Low betweenness, by contrast, signals a more common structural position where the source of social capital is redundancy and commonality of neighbors. A firm with low betweenness occupies a closed network position. An alternative, direct measure of closure is constraint. ${ }^{8}$ Constraint increases when the degree of the focal firm decreases, when the number of distance-two neighbors decreases, and when the clustering of the focal firm's neighborhood increases (Burt, 1992). We use both measures and observe the consistency of our results.

Earlier, we argued that in pooled cross-section open network positions would become more beneficial to firms as the skew of the distribution of possible performance outcomes increased, whereas over time the opposite would hold. We assess the veracity of this prediction by examining the correlation between firms' betweenness and innovation size. To observe network effects in pooled cross-section, each time there a firm innovates, we record the profits of the innovating firm (i.e., total dislocation imposed on other firms minus the cost of its alliance portfolio this period), and the betweenness of the innovating firm. We thus have innovationcentric data. To observe "network strategy" effects, we follow each firm over its entire history, and at the end of the simulation record, for each firm, total profits over this history (i.e., the total dislocations it has imposed on other firms through its innovations minus the total cost it has incurred in making alliances), and the average of its betweenness measured every period. Here we have firm-centric data. Correlations between innovation size and betweenness on the one hand, and total profits and betweenness on the other allow us to compare pooled

\footnotetext{
${ }^{7}$ Betweenness centrality of firm $i, b_{i}$, is the sum, over all possible pairs $k, l \in N-\{i\}$, of the proportion $p_{k, i, l}$ of shortest paths between $k$ and $l$ that run through $i$, i.e., $b_{i}=\sum_{k, l \neq i} p_{k, i, l}$.

${ }^{8}$ Constraint of firm $i, C_{i}$ is defined as $C_{i}=\sum_{j \neq i} \sum_{q \neq i, j}\left(a_{i, j}+a_{i, q} a_{q, j}\right)^{2}$, where $a_{i, j}=1$ if $i$ and $j$ have an alliance and 0 otherwise.
} 
cross-section and within-firm long-run relationships. To observe how these relationships are affected by the skewness of possible performance outcomes, we use as the abscissa the observed skew of the population-level performance distribution. That is, for each value of the parameter $s$, which controls the innovation size distribution, at the end of each simulation run, we calculate the skew of the distribution of observed firm profits. We display Spearman correlations against this variable in the left panel of Figure 4.
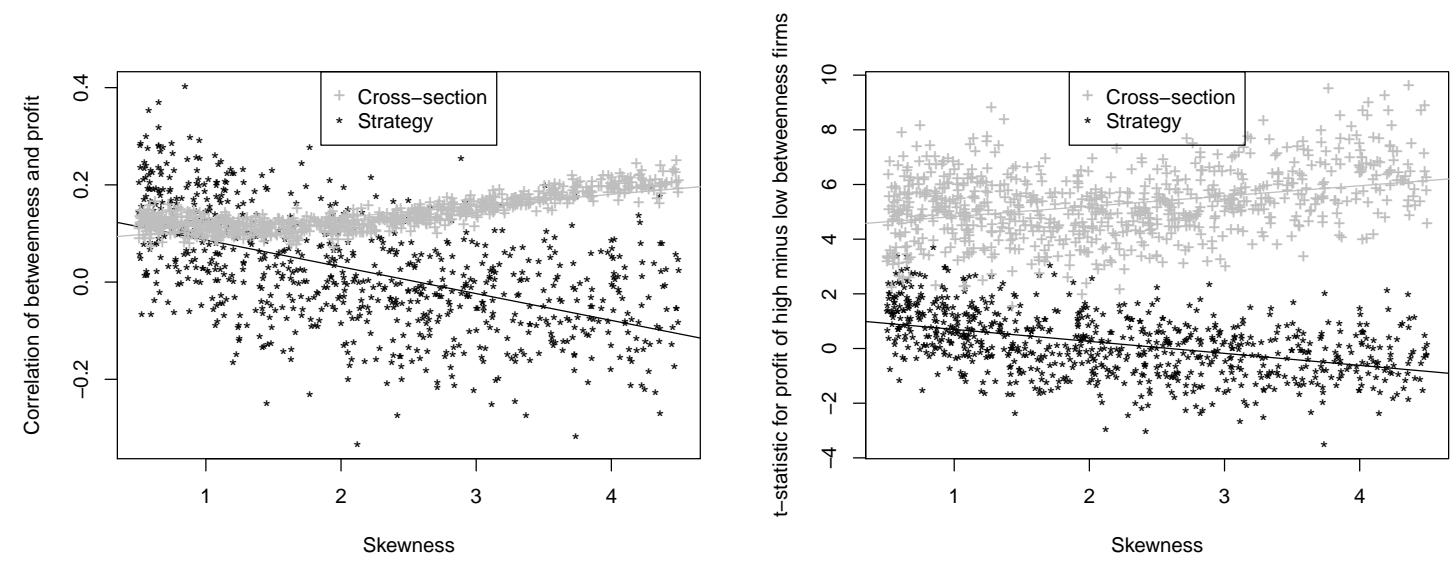

Figure 4: The relationship between betweenness and performance in cross-section and over time, by skewness of the observed distribution of firm profits. Left panel shows correlations between profit and betweenness; right panel displays t-statistics (means over standard errors of differences) of above and below median firm profits, for cross-section ranked by innovation size, for strategy ranked by firm average betweenness over time.

To provide an alternate view of the results, we present the data a second way. The crosssection analysis essentially asks about innovations: "What are the properties of big (versus small) innovations?" By contrast, the strategy analysis asks about firms: "What is the performance of high (versus low) betweenness firms?" We can address those questions directly by comparing large and small innovations, or open-positioned and close-positioned firms. In the first instance, we compare the betweenness of the top and bottom halves of the innovation size distributions. In the second instance we compare total profits for the top and bottom halves of the population of firms ranked by betweenness. To perform these comparisons and assess their statistical significance, we use a simple difference of means test. We report the value of the t-statistic, which is the number of standard errors by which the two sample means are separated. A value of the t-statistic outside (approximately) $[-2,2]$ means rejection of 
the null hypothesis that the two sample means are the same. We display t-statistics against the observed skew of the observed distribution of firm profits on the right panel of Figure 4.

What we observe in the left panel of Figure 4 is that, in pooled cross-section, open network positions are positively correlated with firm performance. Further, this correlation increases in magnitude with the skewness of the population-level distribution of observed firm profits. By comparison, in the long run, while the correlation is positive for low-skew profit distributions, it falls as the skewness of firm profits increases, and becomes negative when skew is high. The right panel, displaying the difference of means test for of top-versus-bottom halves of the population, tells the same story. In cross-section, with innovation-centric data, there is clearly a statistical difference: large innovations are strongly associated with firms holding open positions (as measured by betweenness) and this association grows as the skewness of firm profits increases. Over the long run, using firm-centric data, though, effects are less clear. Statistically, it would be difficult to argue that high-profit firms have more or less open positions than closed-position firms. We note, though, that if there is a trend, the effect of population-level performance skewness on the relationship between open positions and profit is of opposite sign to that seen in cross-section. Consistent with the predictions above,
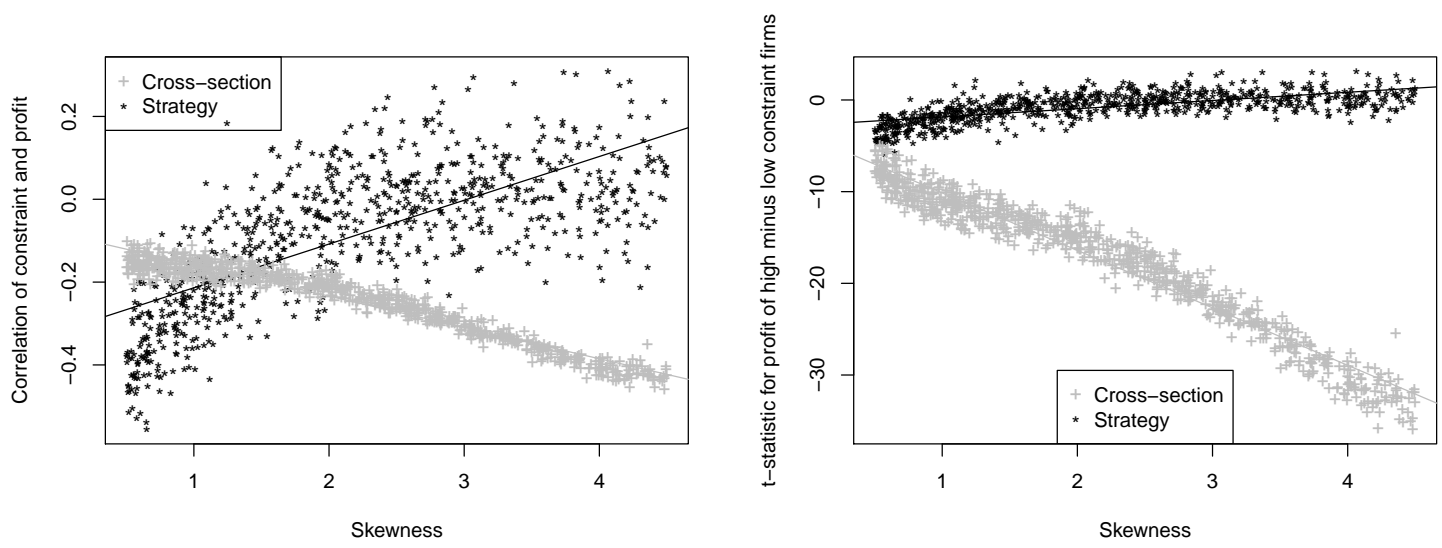

Figure 5: The relationship between constraint and performance in cross-section and over time, by skewness of the observed distribution of firm profits. Left panel shows correlations between profit and constraint; right panel displays t-statistics (means over standard errors of differences) of above and below median firm profits, for cross-section ranked by innovation size, for strategy ranked by firm average constraint over time. 
then, the results indicate that the effects of network position on firm performance in pooled cross-section and over time are contradictory, and that evidence of network effects in pooled cross-section data does not straightforwardly support prescriptions for network strategy over time.

To examine the effects of closed positions directly, we replicate the analysis using constraint rather than betweenness to measure firms' network positions. The results, presented in Figure 5 are analogous to those found in Figure 4 for betweenness. The left panel shows correlations between performance and constraint, plotted against the skewness of the population-level profit distribution. The right panel shows t-statistics for the difference in means: in pooled cross-section we compare the constraint of the top and bottom halves of the innovation size distributions; for the long run, we compare total profits for the top and bottom halves of the population of firms ranked by constraint. As expected, the correlation patterns are reversed from those for betweenness. And, again, the results are consistent with our theoretical predictions.

These simulation results are consistent with the link drawn between network positions and learning modes suggesting that closed positions reduce firm performance variation, while open positions increase it. To assess the alignment of this characterization with the outcomes experienced by our simulated firms, we computed correlations of firms' profit variance with betweenness and constraint. To observe how these relationships are affected by the skewness of the population-level performance distribution, we again use the skew of the observed distribution of firm profits as the abscissa. The correlations are presented in Figure 6 .

The left panel shows that the correlation between firm profit variance and betweeness is positive but decreasing as the skewness of the observed firm performance distribution increases initially, and stabilizes at 0 for skewness $>3$. The right panel shows that the correlation between firm profit variance and constraint, oppostively, is negative but increasing as the skew of the observed firm profit distribution increases initially, and stabilizes at 0 for skewness $>3$. Thus, for skewness $<3$ the profit variance correlations are consistent with the theoretical expectation that closed positions, characterized by high constraint, lower firm performance variance, while open positions, characterized by high betweeness, raise it. For skewness $>3$, the disruptiveness of the innovation regime (controlled by the parameter $s \in[1,30])$ results in all firms experiencing similar performance variance and this reduces the correlations with network position to zero. Firms' profit variance converge as $s$ increases 
because the probability of large innovations of size $s, 1 /(s+1)$, declines, while the probability of small innovations of size $1 / s, s /(s+1)$, increases. The result is that innovations of size $1 / s$ become more frequent, but are too small to differentiate the profitability of innovators from non-innovators, while innovations of size $s$ become large, but are too infrequent to differentiate the profitability of firms over time.

\section{Discussion and conclusion}

We have observed substantial discrepancies in correlations between network position and performance in pooled cross-section and within-firm, over time, and as a result, prescriptions drawn from the two types of correlations would be very different under some conditions. We have advanced an explanation that resides in the nature of performance benefits firms derive from their network positions. And, in particular, whether network positions affect firm performance through its mean or variance.

Open network positions facilitate broad search for emerging innovations and future options vital to exploratory search (Powell et al., 1996). Closed network positions, yield access to the redundant and validating information essential to exploitive search (Dyer and Singh, 1998). Appropriate network positions thus depend on the degree of uncertainty and rate of change
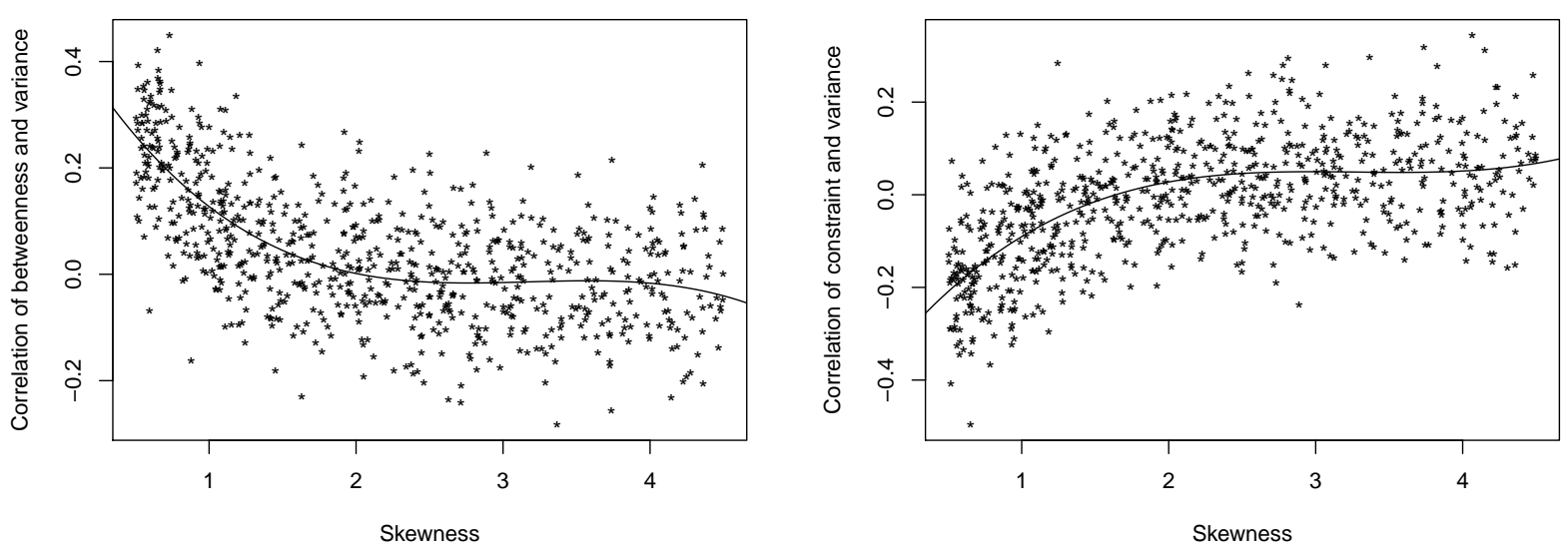

Figure 6: The relationships of variance in firm profits with betweenness and constraint by skewness of the observed distribution of firm profits. 
in the environment (Gilsing et al., 2008; Rowley et al., 2000). Specifically, firms operating in rapidly changing environments will benefit from open network positions, which aid in exploration, while firms in stable environments will benefit from closed network positions, which aid in exploitation.

This link between network positions and learning modes suggests, as we observed, that open and closed network positions affect firm performance distinctly, with closed positions reducing firm performance variation, and open positions increasing it. Closed network positions should therefore benefit firms when the population-level performance distribution favors low firm performance variation, and open network positions when the distribution favors high firm performance variation.

Following March (1991), we proposed that right-skewed distributions of possible outcomes favor firms occupying variance-increasing open network positions in pooled cross-sectional competition for high performance. Over time, however, because high variance also increases exposure to poor outcomes, mean performance for firms sustaining open network positions declines with the right-skewness of the population-level performance distribution. Moreover, because variance-reducing closed network positions provide protection against poor outcomes, the performance benefit of sustaining a closed network position over time increases with the right-skewness of the population-level performance distribution.

To examine these predictions, we designed our model to permit variation in the disruptiveness of the innovation regime - from incremental to radical - in order to alter the rightskewness of the distribution of possible performance outcomes. The possibility of large size innovations generates a right-skewed distribution of possible performance outcomes in which firms occupying open network positions should achieve higher performance in pooled crosssection. In contrast, if only incremental innovations are possible, variance-reducing closed network positions should produce higher performance in cross-section. These predictions are consistent with arguments and pooled cross-section findings in empirical studies of network effects (e.g., Gilsing et al., 2008; Rowley et al., 2000), and our results support them. Our analysis thus identifies performance variability as a general mechanism that can potentially account for the observed empirical findings on firm performance in pooled cross-section.

The results also support the within-firm, over time prediction for both open and closed network positions. Thus, while the correlations for betweenness in pooled cross-section increase with the skewness of the population-level performance distribution, the within-firm 
over time correlations for betweenness decline with this distribution's skewness (see Figure 4). In contrast, the correlations for constraint in pooled cross-section decreased with the skewness of the population-level performance distribution, while the within-firm over time correlations for constraint increased with skewness (see Figure 5). Moreover, the results were largely consistent with theoretical expectation underlying the prectictions that closed positions reduce firm performance variation, while open positions increase it (see Figure 6).

Network strategy prescriptions drawn from the pooled cross-section correlations would thus counsel firms to adopt open network strategies in high-skew innovation regimes where population-level performance is also skewed, but correlations based on firms' long-run strategies indicate that this prescription is exactly opposite to the behavior of firms successful in the long run. Analogously, network strategy prescriptions drawn from the pooled cross-section correlations would imply firms adopt closed network strategies in low-skew innovation regimes where population-level performance also exhibits low-skew, while correlations based on firms' long-run strategies show that this prescription again directly contradicts the behavior of firms successful in the long run.

Although we have focused here on the influential stream of research on network position effects, the phenomenon we articulate is likely to be far more general, applying broadly to firm characteristics (R\&D intensity, for instance) that are likely to affect firm performance through its variance rather than (or in addition to) its mean.

We began with the observation that, while intuitively appealing (and common), drawing network strategy implications from empirical evidence of network performance effects in pooled cross-section is not necessarily warranted. As we explained, this is because network positions may influence both the mean and variance of firm performance. Although strategic prescriptions are warranted if network effects observed empirically in pooled cross-section reflect increases in mean firm performance, if network effects instead reflect increases in firm performance variance, such prescriptions are warranted only if the increase in the odds of achieving high performance are sufficient to compensate for the concomitant increase in the odds of realizing poor performance. Our analysis suggests that network effects may indeed reflect changes in firm performance variance, and moreover, that the increased odds of achieving high performance in cross-section may be insufficient to compensate for the concomitant increase in the odds of realizing poor performance over time. This suggests the exercise of caution in drawing implications for network strategies. 


\section{References}

[1] Abernathy, W.J., and Utterback J.M. 2000. Patterns of industrial innovation. Technology Review, 7: 40-47.

[2] Adriani P., and McKelvey B. 2009. From Gaussian to Paretian thinking: Causes and implications of power laws in organizations. Organization Science, 20:1053-1071.

[3] Ahuja, G. 2000. Collaboration networks, structural holes, and innovation: A longitudinal study. Administrative Science Quarterly, 45: 425-455.

[4] Argote, L. 1999. Organizational Learning: Creating, Retaining and Transferring Knowledge. Boston MA: Kluwer.

[5] Baum J.A.C., Cowan, R. and Jonard, N. 2010. Network-independent partner selection and the evolution of innovation networks. Management Science. 56, 2094-2110.

[6] Baum J.A.C., and Ingram P. 2002. Interorganizational learning and network organization: Toward a behavioral theory of the interfirm. In M. Augier, J.G. March (Eds.). The Economics of Choice, Change, and Organization: Essays in Memory of Richard M. Cyert: 191-218. Cheltenham, UK: Edward Elgar.

[7] Baum J.A.C., McEvily B., and Rowley, T.J. 2010. Better with age? Tie longevity and the performance implications of bridging and closure. Organization Science, doi:10.1287/orsc.1100.0566.

[8] Burt, R. S. 1992. Structural Holes: The Social Structure of Competition. Cambridge: MA: Harvard University Press.

[9] Burt, R. S. 2000. The network structure of social capital. Research in Organizational Behavior, Vol. 22: 345-423. New York: JAI-Elsevier Science Inc.

[10] Coleman, J. S. 1988. Social Capital in the Creation of Human-Capital. American Journal of Sociology, 94: S95-S120.

[11] Coleman, J. 1990. Foundations of the Social Theory. Cambridge, MA: Harvard University Press. 
[12] Dess, G.G., and Beard, D.W. 1984. Dimensions of organizational task environments. Administrative Science Quarterly, 29: 52-73.

[13] Dyer, J.H., and Singh, H. 1998. The Relational View: Cooperative Strategy and Sources of Interorganizational Competitive Advantage. Academy of Management Review, 23: 660-679.

[14] Gilsing,V., Nooteboom, B., Vanhaverbeke, W., Duysters, G., and van den Oord, A. 2008. Network embeddedness and the exploration of novel technologies: Technological distance, betweenness centrality and density. Research Policy, 37: 1717-1731.

[15] Granovetter, M. 1973. The strength of weak ties. American Journal of Sociology, 78: 1360-1380.

[16] Gulati, R. 1995. Social structure and alliance formation patterns: A longitudinal analysis. Administrative Science Quarterly, 40: 619-652.

[17] Gulati, R., and Gargiulo, M. 1999. Where do inter-organizational networks come from? American Journal of Sociology, 104: 1439-1493.

[18] Holland, J.H. 1975. Adaptation in Natural and Artificial Systems. Ann Arbor MI: University of Michigan Press.

[19] Lant, T.K., Milliken, F.J., and Batra, B. 1992. The role of managerial learning and interpretation in strategic persistence and reorientation: An empirical exploration. Strategic Management Journal, 13: 585-608.

[20] Lavie, D., and Rosenkopf, L. 2006. Balancing exploration and exploitation in alliance formation. Academy of Management Journal, 49: 797-818.

[21] Levinthal, D.A., and March, J.G. 1993. The myopia of learning. Strategic Management Journal, 14 (Winter Special Issue): 95-112.

[22] Levitt, B., and March, J.G. 1988. Organizational learning. Annual Review of Sociology, 14: 319-340.

[23] March, J. G. 1991. Exploration and exploitation in organizational learning. Organization Science, 2: 71-87. 
[24] McEvily, B., and Zaheer, A. 1999. Bridging ties: A source of firm heterogeneity in competitive capabilities. Strategic Management Journal, 20: 1133-1156.

[25] Mitsuhashi, H. 2003. Effects of the social origins of alliances on alliance performance. Organization Studies, 24: 321-339.

[26] Powell, T. C. 2003. Varieties of competitive parity. Strategic Management Journal, 24: 61-86.

[27] Powell, W. W., White, D., Koput, K., and Owen-Smith, J. 2005. Network dynamics and field evolution: The growth of interorganizational collaboration in the life sciences. American Journal of Sociology, 110: 1132-1205.

[28] Rosenkopf, L. and Nerkar, A. 2001. Beyond local search: Boundary-spanning, exploration, and impact in the optical disk industry. Strategic Management Journal, 22: 287306.

[29] Rosenkopf, L., and Almeida, P. 2003. Overcoming local search through alliances and mobility. Management Science, 49: 751-766.

[30] Rothaermel, F., and Deeds, D.L. 2004. Exploration and exploitation alliances in biotechnology: A system of new product development. Strategic Management Journal, 25: 201221.

[31] Rowley, T., Behrens, D., and Krackhardt, D. 2000. Redundant governance structures: An analysis of structural and relational embeddedness in the steel and semiconductor industry. Strategic Management Journal, 21: 369-386.

[32] Tushman, M.L., and Anderson, P. 1986. Technological discontinuties and organizational environments. Administrative Science Quarterly, 31, 439-465.

[33] Uzzi, B. 1996. The sources and consequences of embeddedness for the economic performance of organizations: The network effect. American Sociological Review, 61: 674-698.

[34] Uzzi, B. 1997. Social structure and competition in interfirm networks: The paradox of embeddedness. Administrative Science Quarterly, 42: 35-67. 
[35] Van de Ven, A. H. 1976. On the nature, formation and maintenance of relations among organizations. Academy of Management Review, 1: 24-36.

[36] Walker, G., Kogut, B., and Shan, W. 1997. Social capital, structural holes and the formation of an industry network. Organization Science, 8: 109-125.

[37] Yelle, L. E. 1979. The learning curve: Historical review and comprehensive survey. Decision Sciences, 10: 302-328. 


\section{The UNU-MERIT WORKING Paper Series}

2012-01 Maastricht reflections on innovation by Luc Soete

2012-02 A methodological survey of dynamic microsimulation models by Jinjing Li and Cathal O'Donoghue

2012-03 Evaluating binary alignment methods in microsimulation models by Jinjing Li and Cathal O'Donoghue

2012-04 Estimates of the value of patent rights in China by Can Huang

2012-05 The impact of malnutrition and post traumatic stress disorder on the performance of working memory in children by Elise de Neubourg and Chris de Neubourg

2012-06 Cross-national trends in permanent earnings inequality and earnings instability in Europe 1994-2001 by Denisa Maria Sologon and Cathal O'Donoghue

2012-07 Foreign aid transaction costs by Frieda Vandeninden

2012-08 A simulation of social pensions in Europe by Frieda Vandeninden

2012-09 The informal ICT sector and innovation processes in Senegal by Almamy Konté and Mariama Ndong

2012-10The monkey on your back?! Hierarchical positions and their influence on participants' behaviour within communities of learning by Martin Rehm, Wim Gijselaers and Mien Segers

2012-11 Do Ak models really lack transitional dynamics? by Yoseph Yilma Getachew

2012-12 The co-evolution of organizational performance and emotional contagion by $\mathrm{R}$. Cowan, N. Jonard, and R.Weehuizen

2012-13 "Surfeiting, the appetite may sicken": Entrepreneurship and the happiness of nations by Wim Naudé, José Ernesto Amorós and Oscar Cristi

2012-14 Social interactions and complex networks by Daniel C. Opolot

2012-15 New firm creation and failure: A matching approach by Thomas Gries, Stefan Jungblut and Wim Naudé

2012-16 Gains from child-centred Early Childhood Education: Evidence from a Dutch pilot programme by Robert Bauchmüller

2012-17 Highly skilled temporary return, technological change and Innovation: The Case of the TRQN Project in Afghanistan by Melissa Siegel and Katie Kuschminder

2012-18 New Technologies in remittances sending: Opportunities for mobile remittances in Africa Melissa Siegel and Sonja Fransen

2012-19 Implementation of cross-country migration surveys in conflict-affected settings: Lessons from the IS Academy survey in Burundi and Ethiopia by Sonja Fransen, Katie Kuschminder and Melissa Siegel

2012-20 International entrepreneurship and technological capabilities in the Middle East and North Africa by Juliane Brach and Wim Naudé

2012-21 Entrepreneurship, stages of development, and industrialization by Zoltan J. Ács and Wim Naudé

2012-22 Innovation strategies and employment in Latin American firms by Gustavo Crespi and Pluvia Zuniga

2012-23 An exploration of agricultural grassroots innovation in South Africa and implications for innovation indicator development by Brigid Letty, Zanele Shezi and Maxwell Mudhara

2012-24 Employment effect of innovation: microdata evidence from Bangladesh and Pakistan by Abdul Waheed 
2012-25 Open innovation, contracts, and intellectual property rights: an exploratory empirical study by John Hagedoorn and Ann-Kristin Ridder

2012-26 Remittances provide resilience against disasters in Africa by Wim Naudé and Henri Bezuidenhout

2012-27 Entrepreneurship and economic development: Theory, evidence and policy by Wim Naudé

2012-28 Whom to target - an obvious choice? by Esther Schüring and Franziska Gassmann

2012-29 Sunk costs, extensive R\&D subsidies and permanent inducement effects by Pere Arqué-Castells and Pierre Mohnen

2012-30 Assessing contingent liabilities in public-private partnerships (PPPs) by Emmanouil Sfakianakis and Mindel van de Laar

2012-31 Informal knowledge exchanges under complex social relations: A network study of handloom clusters in Kerala, India by Robin Cowan and Anant Kamath

2012-32 Proximate, intermediate and ultimate causality: Theories and experiences of growth and development by Adam Szirmai

2012-33 Institutions and long-run growth performance: An analytic literature review of the institutional determinants of economic growth by Richard Bluhm and Adam Szirmai

2012-34 Techniques for dealing with reverse causality between institutions and economic performance by Luciana Cingolani and Denis de Crombrugghe

2012-35 Preliminary conclusions on institutions and economic performance by Denis de Crombrugghe and Kristine Farla

2012-36 Stylized facts of governance, institutions and economic development. Exploring the institutional profiles database by Bart Verspagen

2012-37 Exploring the Panel Components of the Institutional Profiles Database (IPD) by Luciana Cingolani and Denis de Crombrugghe

2012-38 Institutions and credit by Kristine Farla

2012-39 Industrial policy for growth by Kristine Farla

2012-40 Explaining the dynamics of stagnation: An empirical examination of the North, Wallis and Weingast approach by Richard Bluhm, Denis de Crombrugghe and Adam Szirmai

2012-41 The importance of manufacturing in economic development: Past, present and future perspectives by Wim Naudé and Adam Szirmai

2012-42 Lords of Uhuru: the political economy of elite competition and institutional change in post-independence Kenya by Biniam Bedasso

2012-43 Employment and wages of people living with HIV/AIDS by Pilar García-Gómez, José M. Labeaga and Juan Oliva

2012-44 Prescriptions for network strategy: Does evidence of network effects in crosssection support them? by Joel A.C. Baum, Robin Cowan, and Nicolas Jonard 